\section{Compliance with the World Health Organization Hand Hygiene Technique: A Prospective Observational Study}

Studies on compliance with hand hygiene technique commonly focus on observations regarding adherence of healthcare workers to the 5 moments outlined by the World Health Organization (WHO) guidelines. ${ }^{1}$ These guidelines also provide guidance on the proper technique for the use of hand rub, consisting of 6 steps to ensure the complete coverage of the hands. Several studies have provided strong evidence for increased bacterial killing using this technique, ${ }^{2-5}$ but compliance with all 6 steps has not been evaluated. Therefore, we aimed to assess compliance of healthcare workers with the recommended hand hygiene technique.

This prospective observational study was performed at the University Hospital Basel, a tertiary academic medical care center in Switzerland that admits $>32,000$ patients annually. During defined study periods from 2010 to 2013, hand hygiene observations were conducted on 15 different wards: 5 medical and 5 surgical wards, as well as 2 wards belonging to the emergency department, 2 wards belonging to the intensive care units, and the bone marrow transplant unit. The study was approved by the institutional review board as part of the quality assurance program.

All hand hygiene observations were performed by 3 trained researchers over 520 hours of direct observation of performance of hand hygiene techniques at the 5 moments of hand hygiene. The 5 moments of hand hygiene as outlined by the $\mathrm{WHO}^{1}$ are (1) before touching a patient, (2) after touching a patient, (3) after touching patient surroundings, (4) after body fluid exposure risk, and (5) before clean/aseptic procedure"). The individual steps of the hand hygiene technique as outlined by the WHO are (1) rubbing hands palm to palm, (2) palm to palm with fingers interlaced, (3) right palm over left dorsum with interlaced fingers and vice versa, (4) back of fingers to opposing palms with fingers interlocked, (5) rotational rubbing of left thumb clasped in right palm and vice versa, and (6) rotational rubbing backwards and forwards with clasped fingers of right hand in left palm and vice versa). ${ }^{1,6}$

Furthermore, information regarding age, profession, and duration of employment at our institution was recorded. Age was categorized as <26 years, $26-35$ years, 36-45 years, $46-55$ years, and $>55$ years. Duration of employment was categorized as $0-5$ years, $6-10$ years, $11-20$ years, and $>20$ years.

The primary outcome was compliance with all 6 steps of the hand hygiene technique. The $\chi^{2}$ test was used for comparisons of proportions, and odds ratios (ORs) were calculated using univariable logistic regression models and Stata statistical software, version 12.0 (Stata Corp, College Station, Texas). Two-sided $P$ values $<.05$ were considered significant.
Overall, 2,662 hand hygiene opportunities were observed, mostly among nurses $(65.3 \%, 1,737$ of 2,662), followed by doctors $(21.7 \%, 579$ of 2,662) and other healthcare workers $(13.0 \%, 346$ of 2,662$)$. The most common indication was "after touching a patient" $(41.9 \%, 1,114$ of 2,662$)$, followed by "before touching a patient" (31.9\%, 848 of 2,662), "after touching patient surroundings" (11.0\%, 292 of 2,662), “after body fluid exposure risk" (9.0\%, 240 of 2,662), and "before clean of aseptic procedure" $(6.3 \%, 168$ of 2,662).

\section{COMPLIANCE WITH HAND HYGIENE IN D ICA T I ON S}

Hand hygiene was performed in $93.2 \%$ of all opportunities $(2,480$ of 2,662). Compliance rates were highest in the intensive care units (100\%, 193 of 193), followed by the emergency department $(94.8 \%, 255$ of 269$)$, the medical wards $(94.0 \%$, 1,225 of 1,303), and the surgical wards $(90.0 \%, 807$ of 897$)$ $(P<.001)$. No differences regarding compliance in respect to profession were identified (nurses $93.6 \%, 1,626$ of 1,737, doctors $91.5 \%$, 530 of 579 , others $93.6 \%, 324$ of 346 ).

\section{COMPLIANCE WITH HAND HYGIENE TECHNIQUE}

Compliance with all 6 steps of hand hygiene technique was $8.5 \%$, the majority of healthcare workers adhered to steps 2 and 3 (Table). Profession was not associated with compliance with hand hygiene technique (nurses $9.0 \%, 156$ of 1,737, doctors $6.9 \%, 40$ of 579 , others $9.0 \%, 31$ of $346, P=.288$ ). Healthcare workers $\leq 25$ years of age showed higher compliance with the correct technique than older age groups (OR, $0.84 ; 95 \% \mathrm{CI}, 0.74-0.97 ; P=.016)$, and compliance with all 6 steps decreased with increasing duration of employment at our institution (OR, $0.68 ; 95 \% \mathrm{CI}, 0.54-0.87 ; P=.002$ ).

No differences in compliance with hand hygiene indications or technique were detected over the study period (data not shown).

While compliance with hand hygiene indications was high at our institution, proper technique for use of alcohol-based hand rub was performed in $<10 \%$ of all hand hygiene opportunities. Younger healthcare workers and those employed at our institution for shorter time periods were more likely to adhere to all 6 hand hygiene steps. This observation is concerning, as noncompliance with the proper technique for using hand rub may result in failure to cover all skin surfaces and, hence, insufficient bacterial killing. 3,7

These results mirror findings from a previous study revealing that repeated training programs on the proper hand hygiene technique should be offered throughout professional life to ensure greater degrees of reduction of bacterial densities. ${ }^{8}$ 
TABLE 1. Compliance with the World Health Organization Hand Hygiene Technique

\begin{tabular}{l} 
Opportunities $(\mathrm{N}=2,662)$ \\
\cline { 2 - 2 }
\end{tabular}

Important limitations of our study include lack of standardization of types of care before performance of direct observation as well as an absence of measures to avert a Hawthorne observation effect. ${ }^{9}$ The latter limitation possibly explains the high compliance rate with hand hygiene indications observed at our institution while underscoring the low compliance rate with the hand hygiene technique.

In conclusion, compliance with hand hygiene does not necessarily correlate with proper WHO-recommended technique. The decline of compliance with increasing age of healthcare workers and duration of employment point to the high level of training needed to ensure performance of all 6 steps of the hand hygiene technique. Surveillance programs focusing on adherence of healthcare workers to hand hygiene indications may overestimate the efficacy of such interventions.

\section{ACKNOWLEDGMENTS}

Financial support: No commercial funding was received for the study.

Potential conflicts of interest: No author has any conflict of interest relevant to this article and no financial interest in this manuscript.

\section{Sarah Tschudin-Sutter, MD, MSc; ${ }^{1}$ Daniel Sepulcri; ${ }^{1}$ Marc Dangel, MPH; ${ }^{1}$ Heinz Schuhmacher, $\mathrm{RN}^{1}$ Andreas F. Widmer, MD, MSc ${ }^{1}$}

Affiliation: Division of Infectious Diseases and Hospital Epidemiology, University Hospital Basel, Basel, Switzerland.

Address correspondence to Dr. Andreas F. Widmer, Division of Infectious Diseases and Hospital Epidemiology, University Hospital Basel, Petersgraben 4, CH-4031 Basel, Switzerland (Andreas.Widmer@uhbs.ch).

Previous presentation of the data: The abstract was presented at the 24th European Congress of Clinical Microbiology and Infectious Diseases, Barcelona, Spain 2014 and at the Meeting of the Swiss Society for Infectious Diseases, Aarau, Switzerland 2014.

Received: September 28, 2014; Accepted: December 2, 2014; electronically published January 20, 2015

Infect Control Hosp Epidemiol 2015;36(4):482-483

(c) 2015 by The Society for Healthcare Epidemiology of America. All rights reserved. 0899-823X/2015/3604-0019. DOI: 10.1017/ice.2014.82

\section{REFERENCES}

1. World Health Organization. WHO guidelines on hand hygiene in health care, first global patient safety challenge: clean care is safer care. Geneva, Switzerland: World Health Organization, 2009.

2. Carabin H, Gyorkos TW, Soto JC, Joseph L, Payment P, Collet JP. Effectiveness of a training program in reducing infections in toddlers attending day care centers. Epidemiology 1999;10:219-227.

3. Widmer AE, Dangel M. Alcohol-based handrub: evaluation of technique and microbiological efficacy with international infection control professionals. Infect Control Hosp Epidemiol 2004;25:207-209.

4. Kramer A, Rudolph P, Kampf G, Pittet D. Limited efficacy of alcohol-based hand gels. Lancet 2002;359:1489-1490.

5. Ayliffe GA, Babb JR, Quoraishi AH. A test for 'hygienic' hand disinfection. J Clin Pathol 1978;31:923-928.

6. European standard EN 1500. Chemical disinfectants and antiseptics. Hygienic handrub. Test method and requirements. Brussels: European Committee for Standardization, 1997.

7. Widmer AF, Conzelmann M, Tomic M, Frei R, Stranden AM. Introducing alcohol-based hand rub for hand hygiene: the critical need for training. Infect Control Hosp Epidemiol 2007;28:50-54.

8. Tschudin Sutter S, Frei R, Dangel M, Widmer AF. Effect of teaching recommended World Health Organization technique on the use of alcohol-based hand rub by medical students. Infect Control Hosp Epidemiol 2010;31:1194-1195.

9. Eckmanns T, Bessert J, Behnke M, Gastmeier P, Ruden H. Compliance with antiseptic hand rub use in intensive care units: the Hawthorne effect. Infect Control Hosp Epidemiol 2006;27:931-934. 